\title{
Use of the FW-1 Water Level Recorder for Control of Electrical Equipment
}

\author{
R.E. WILSON, A. DOLPHIN, AND J.R. SIMANTON
}

\section{Abstract}

A simple, inexpensive, and positive on/off control device can be added to the FW-1 water level recorder for activation of electrical instrumention used in rangeland hydrologic investigations. The device utilizes existing FW-1 gearing and readily available brass and aluminum parts and can be modified to perform over a wide range of water stage heights.

Automated rangeland hydrologic data collection is necessary to quantify watershed runoff, erosion, and water quality responses to management or improvement practices. On rangeland some automatic sampling or recording equipment must be activated only when flow occurs in washes or streams. In other situations, such as on perennial streams, sampler activation is necessary when the stream flow rises to a certain level. The $\mathrm{FW}-\mathrm{I}^{*}$ recorder is a popular and simple device to measure water depth through weirs and flumes and easily adapted for control of electrical sampling equipment. The Aridland Watershed Management Research Management Research Unit developed a simple, inexpensive, on/off control to activate, directly from the FW-1 recorder, electrically powered instrumention. The control does not interfere with the FW-1 operation and can be adjusted in increments of $3 \mathrm{~mm}(0.01$ $\mathrm{ft}$.) to any desired stage height up to $3.05 \mathrm{~m}$ ( $10 \mathrm{ft}$ ). This control has been used to activate automatic water quality sampling equipment at the Walnut Gulch Experimental Watershed in southeastern Arizona.

The control uses the 1:12 gear supplied with the FW-1 recorder; a $0.95 \times 1.90 \times 0.32(3 / 8 \times 3 / 4 \times 1 / 8$ in $)$ brass lug; a snap-action,

Authors are engineering technician, machinist, and hydrologist, USDA-ARS. Aridland Watershed Management Research Unit, 2000 East Allen Road, Tucson, Arizona 85719.

Manuscript accepted 2 April 1986. micro-switch (Unimax Mfg No. 2TM-4*); and a switch bracket formed from a short length of $1 \times 5.00 \times 0.32 \mathrm{~cm}(1 / 2 \times 2 \times 1 / 8$ in $)$ aluminum $\mathrm{H}$-beam. The brass lug ( 1 in Figure 1 ) is soldered to the 1:12 gear (2) which is meshed to the drive gear of the FW-1 recorder. The switch (3) is attached to the aluminum bracket (4) and this assembly is mounted on the recorder so that the brass lug will operate the switch by depressing or releasing the switch pin plunger. With this arrangement, as the recorder float rises or falls, the brass lug rotates, depressing or releasing the switch pin plunger. A great number of on/ off combinations are possible and can be determined by varying the length of the brass lug, adjusting the 1:12 gear, or a combination of the two. The desired on/off stage is set by loosening and repositioning the 1:12 gear on its shaft. With a $30.5 \mathrm{~cm}$ (1 ft) circumference float tape wheel on the recorder, the $1: 12$ gear revolves once with a $3.05 \mathrm{~m}(10 \mathrm{ft})$ change in stage. Because the $1.91 \mathrm{~cm}(3 / 4 \mathrm{in})$ long lug contacts the switch pin plunger for about $30.5 \mathrm{~cm}$ (1 ft) of stage change, an on/off setting of near 0.0 stage would make the maximum operable stage about $2.74 \mathrm{~m}(9 \mathrm{ft})$ before the lug would again contact the switch. When the on/off stage is set near $30.5 \mathrm{~cm}(1 \mathrm{ft})$ the maximum operable stage is about $3.05 \mathrm{~m}(10 \mathrm{ft})$. Higher on/ off stages may be obtained by lengthening the lug but the operable stage range will be reduced. For installation where the water level stage can drop below 0.0 , a float stop must be installed to keep the lug on the switch pin plunger.

The advantages of this control device are: simple construction; reliable operation; easy, positive, and accurate on/off stage height adjustments; no power drain; no interference with water level recorder operation; and low cost (about $\$ 2.00$ ).

*Use of a trade name or model type does not imply endorsement by the U.S. Government but is used for the reader's benefit.

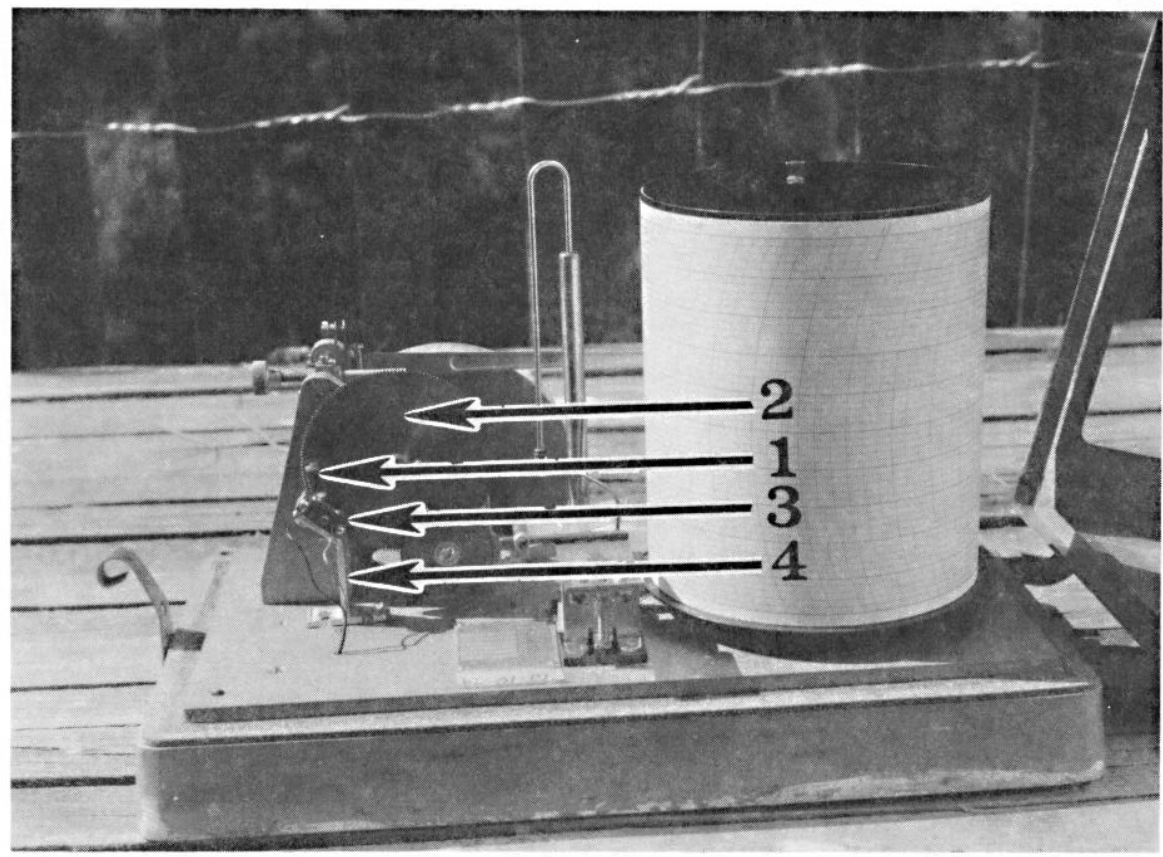

Fig. 1. FW-1 Water Level Recorder with on/off switch. (1) brass lug, (2) gear, (3) micro-switch, (4) alum. H-beam). 